\title{
Entrevista com Marcelo D'Salete
}

Joelma Santana Siqueira (Universidade Federal de Viçosa)

Vivaldo Andrade dos Santos (Georgetown University)

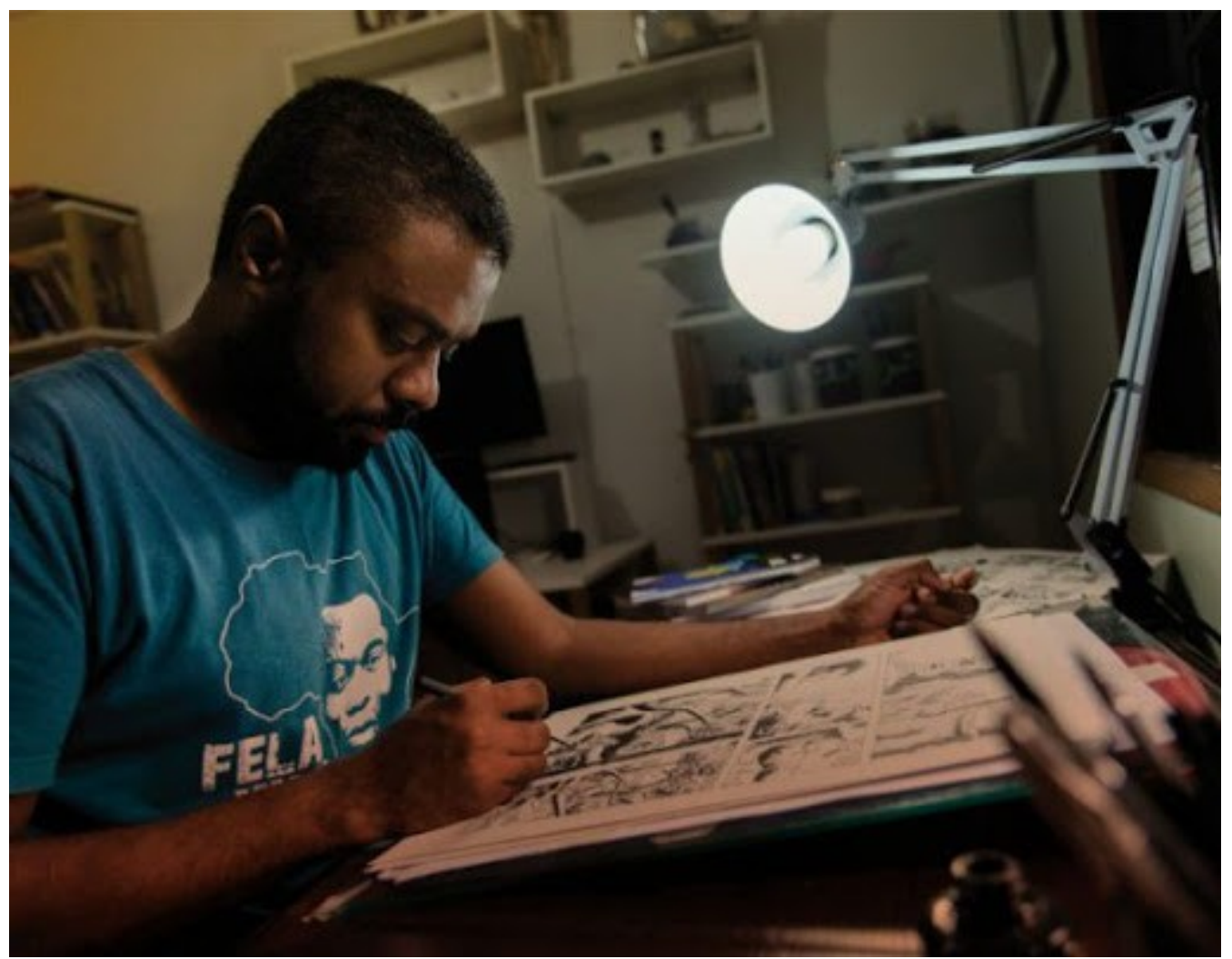

Foto: Rafael Roncato. Fonte: Alumni USP. Disponível em: http://www.alumni.usp.br/alumni-emdestaque-marcelo-dsalete/.

Marcelo D'Salete (1979) é autor de histórias em quadrinhos, ilustrador e professor. Estudou design gráfico e é graduado e mestre em artes plásticas. Sua obra Cumbe, publicada em 2014 pela editoria Veneta, aborda o período colonial e a resistência negra contra a escravidão no Brasil. Publicada em Portugal, França, Áustria, Itália, Espanha e EUA (Fantagraphics), foi selecionada pelo PNLD literário de 2019 para o Ensino Médio, Plano Ler + , recomendação de leitura para escolas de Portugal e premiada no Eisner Awards 2018 na categoria Best U. S. Edition of International Material. Angola Janga - Uma história de Palmares, sobre os antigos mocambos da Serra da Barriga, mais conhecidos como Quilombo dos Palmares, também publicada pela editora Veneta

Gláuks: Revista de Letras e Artes - jul/dez. 2020 -v. 20, n. 2 
em 2017, foi publicada na França, Portugal, Áustria, Espanha, Polônia e EUA. Ganhou o Prêmio Grampo Ouro 2018, HQMIX 2018, Jabuti 2018 e o Rudolph Dirks Award 2019 (Melhor Roteiro - América do Sul); selecionada pelo PNLD literário de 2019 para o Ensino Médio. Encruzilhada, relançada em 2016 pela editora Veneta, versa sobre violência, jovens negros e discriminação em grandes cidades.

1. Prezado Marcelo D'Salete, somos muito gratos a você por nos conceder essa entrevista para o presente dossiê da Gláuks dedicado ao tema "A literatura brasileira no exterior". Para iniciarmos, pedimos que nos fale sobre como é escrever e publicar literatura no Brasil.

Tenho publicado obras de histórias em quadrinhos desde o começo dos anos 2000. A minha formação passa por um curso de artes gráficas e depois pelo curso de artes plásticas. Primeiramente, publiquei em revistas mix, com diversos autores, inicialmente aqui no Brasil e depois também no exterior. A partir de 2008, comecei a publicar obras somente com histórias minhas. Surgiu o livro Noite Luz, de 2008, e Encruzilhada, de 2011, esses dois trabalhos num contexto bem urbano. Depois vieram os livros Cumbe, de 2014, e o livro Angola Janga, de 2017.

Escrever, desenhar, criar obras no formato de livro de quadrinhos no Brasil é algo que, inicialmente, depende bastante de gana e vontade de criar dentro dessa linguagem. Simbolicamente, depois de alguns anos, você pode ter um retorno muito positivo disso. Agora, geralmente o retorno financeiro é algo bem mais demorado e difícil. Creio que desde quando comecei, por volta de 2002, imagino que somente agora, vinte anos depois, eu posso dizer que boa parte da minha renda vem também dos quadrinhos e dos livros, de participação em eventos, de convites para outros projetos também. Mas tudo em grande parte a partir da imagem que os quadrinhos possibilitam.

Sobre a publicação no exterior, esse contato pode ser feito pelo próprio artista com editores de fora. Foi assim quando eu publiquei inicialmente na Argentina. Mandei um e-mail para a editora, eles gostaram do material, resolveram publicar algumas histórias e depois o livro Noite luz, em 2008. Hoje, eu e a editora contamos com um

Gláuks: Revista de Letras e Artes-jul/dez. 2020 - v. 20, n. 2 
agente literário. O livro é publicado, por exemplo, aqui no Brasil e logo depois o agente literário mostra as obras para outros editores em feiras, eventos etc.

\section{Você considera que há diferenças que mereçam ser destacadas entre a recepção que sua obra tem no Brasil e a que tem no exterior?}

No Brasil, os meus primeiros livros foram lidos, logo quando lançados, por um público que gostava muito de quadrinhos. Pessoas que estavam muito interessados em ver autores novos. Depois, principalmente no caso dos últimos dois livros, penso que eles alcançaram um público que vai além do leitor que lê apenas quadrinhos. É um público interessado também em literatura, cinema, artes em geral. Pessoas muito interessadas também em rever a nossa história e a sociedade brasileira atual. O público no exterior muitas vezes é formado por pessoas que já conhecem algo ou têm curiosidade pela nossa história.

No estrangeiro foram publicados o livro Angola Janga e Cumbe. Então, são livros que, de certo modo, apresentam uma perspectiva da história do Brasil que é diferente da perspectiva de autores mais antigos e consagrados. Agora, já me deparei com leitores no exterior, em lançamentos, que consideravam essas narrativas algo bem específico da história do Brasil.

E, na verdade, quando eu penso nas obras Cumbe e Angola Janga, sei que é algo brasileiro, sim, mas não é de uma experiência estritamente brasileira que a gente está falando ali. A diáspora africana forçada devido ao tráfico transatlântico de pessoas foi uma experiência comum a grande parte da América e afetou grande parte do planeta. Então, é uma questão que se conecta com uma experiência da diáspora negra no mundo, nos últimos séculos, e se conecta com a necessidade de conhecer essas narrativas ainda hoje, seja a partir das antigas colônias, seja a partir das antigas metrópoles também, que tem a sua cota de responsabilidade imensa no que foi o tráfico. 
3. Qual a importância da tradução, sobretudo, para o escritor que escreve em português?

A tradução é a forma pela qual o livro pode ser apresentado para leitores fora do Brasil. Então, é algo essencial para ver a sua obra circulando em outros locais e onde há uma discussão muito grande sobre temas que me interessam.

\section{Quais são os desafios para ser publicado no exterior ou ser traduzido para outra língua?}

Inicialmente, pensei em publicar as minhas obras apenas localmente. Todo autor, imagino, gosta de saber que suas obras circulam bem e são lidas em seu entorno. Meu foco era dialogar com as pessoas daqui. No entanto, a publicação e premiações fora do Brasil possibilitaram um alcance ainda maior dos livros dentro e fora do país. Com certeza, ser publicado fora do país não foi uma realização apenas minha, mas é devido ao modo como o livro é recebido pelos leitores, pela crítica, editores etc.

\section{5. "Traduttore, traditore". Como é ler sua obra traduzida para outro idioma? Destacaria algum exemplo?}

Eu pude acompanhar um pouco do trabalho de tradução conversando com alguns tradutores. Acabei conversando, principalmente, com a tradutora para o alemão, Lea Hübner. Algo que percebi, vendo algumas traduções, é como alguns termos são específicos e relacionados a história de um local. Isso apareceu bastante no contexto de tradução do Cumbe e do Angola Janga para o alemão, um pouco para o francês e, também, para o inglês, principalmente.

Nesse caso, apareceu as diversas formas como compreendemos o termo negro em diferentes países. Aqui no Brasil a palavra negro era, até final do século XIX, uma palavra utilizada de uma forma extremamente pejorativa, indicando geralmente pessoas que não tinham nenhuma cidadania e que eram consideradas coisas, algo que pertence a outra pessoa. Quando chegamos no século XX, década de 60, 70, no Brasil, temos uma

Gláuks: Revista de Letras e Artes-jul/dez. 2020 - v. 20, n. 2 
politização desse termo a partir do movimento negro. As pessoas reutilizam o termo negro de uma forma positiva. Isso seria algo semelhante àquela frase em inglês "black is beautiful". No Brasil foi escolhido o termo negro. Inclusive, está em músicas famosas da MPB, Elis Regina e outros.

Enfim, eu percebi que esse termo, quando era utilizado em outras línguas, como no inglês nigger ou black, havia uma preferência por utilizar o termo black, um termo mais recente, e não nigger, que é justamente um termo histórico muito pejorativo. Então, é muito interessante perceber essa sutileza da língua e como ela adquire diferentes nuances de acordo com o local. Aqui no Brasil, utilizamos negro. Embora a palavra tenha sido ressignificada e politizada, ela ainda carrega para muitas pessoas, desconhecedoras desse processo, algo depreciativo, ruim, como se você não pudesse nomear a pessoa daquele modo. E aí, claro, as pessoas começam a utilizar uma grande variedade de outros termos, como mestiço, moreno e vários outros justamente para evitar o negro, por ter essa história tão profunda e estigmatizante dentro do nosso contexto.

\section{Existe uma "literatura nacional”, presa a um país, a uma região, a uma língua?}

Eu penso que quadrinhos é um meio de contar histórias e de aproximar as pessoas a partir dessas histórias. Tentamos fazer com que, ao contar essas narrativas, possamos nos humanizar a partir delas. É um modo de conhecer o outro e poder, a partir disso, vislumbrar outros horizontes. Agora, as histórias muitas vezes, mas não necessariamente, estão conectadas com locais, localizadas em determinado tempo. Por mais que ela fale de algo que extrapola esse local e esse tempo, muitas vezes grande parte do substrato dessa obra começa a partir desse local e desse tempo. Então, eu penso que a literatura, de certo modo, embora ela possa investigar diferentes espaços e tempos a partir da ficção, e é importante que a gente garanta isso, por outro lado ela é uma via incrível, uma via formidável de investigar histórias e momentos e poder aproximar isso do nosso momento.

Gláuks: Revista de Letras e Artes - jul/dez. 2020 -v. 20, n. 2 
7. Seu fazer literário busca responder a alguma urgência presente na realidade social brasileira que você gostaria de destacar?

Meu trabalho em quadrinhos é expressão da minha vivência e interesses, é parte do meu projeto de vida. A minha história foi e é próxima de grupos que discutem o racismo, a desigualdade social e violência enorme que temos no Brasil. De certo modo, creio que grande parte do que eu faço dialoga com esses interesses e questões. Eu faço quadrinhos porque eu aprecio demais essa linguagem, o desenho, a possibilidade de contar narrativas pela poesia das imagens. Essa forma de narrativa, para mim, é muito rica, bonita e instigante. Além disso, é algo muito gratificante poder compartilhar um modo de ver o mundo e nossas relações. De certo modo, o artista acaba inserindo na obra um pouco das suas crenças, dilemas, dúvidas e paixões também.

Entrevista transcrita por Laís de Oliveira Moreira. 